\title{
Study on prevalence of anemia in pregnant women in labour
}

\author{
Neelam Goyal*, Harshita Pandey
}

Department of Obstetrics and Gynecology, Government Doon Medical College, Dehradun, Uttarakhand, India

Received: 14 May 2020

Accepted: 18 May 2020

\section{*Correspondence:}

Dr. Neelam Goyal,

E-mail: neelamgoyal1963@gmail.com

Copyright: (c) the author(s), publisher and licensee Medip Academy. This is an open-access article distributed under the terms of the Creative Commons Attribution Non-Commercial License, which permits unrestricted non-commercial use, distribution, and reproduction in any medium, provided the original work is properly cited.

\section{ABSTRACT}

Background: In the developing world Nutritional deficiency anaemia is the commonest finding in pregnant women. Lack of balanced diet, poor socio-economic status, repeated pregnancies and illiteracy are seen associated with Anaemia commonly. Anaemia itself results in maternal morbidities and poor pregnancy outcomes. Neonatal morbidities also have a direct equation with anaemia. It is a study done on pregnant women in labour with the sole objective to estimate the prevalence of anaemia amongst them and associated fetomaternal morbidities.

Methods: It is a prospective observational study done on 300 pregnant women presenting in labour from October 2019-Decemebr 2019, in Government Doon Medical College, Dehradun. These women belonged to Dehradun and surrounding hilly areas of Uttarakhand. Their haemoglobin levels (complete blood count) were assessed at the time of admission along with other routine investigations. They were also assessed for associated pre and post-delivery morbidities and mortality.

Results: In this study, out of 300 pregnant women presenting in labour from October 2019 to December 2019, in Government Doon Medical College Dehradun, the incidence of anaemia was found to be very high (70\%). Severely anaemic patient group was found to have maximum number of fetomaternal complications and blood transfusion requirements.

Conclusions: Despite all the maternal welfare programmes being run at National levels, it is being observed that there is a high unacceptable prevalence of anaemia in pregnant women. This increases their morbidity and mortality. It is a huge burden on hospital finances and blood bank for blood transfusions which are preventable. There is need to strengthen our health care system at primary level for pregnant women and teenage girls.

Keywords: Anaemia, Maternal anaemia, Pregnancy, Prevalence

\section{INTRODUCTION}

It has been a challenge in developing world and in India to fight anaemia in pregnant women. The prevalence in India is about $65 \%-75 \% .^{1,2}$ In the developed world it is only about $14 \%$.

Anaemia has been seen to be the most common nutritional deficiency disorder in pregnant women. It is the second most common cause of maternal death in India, and about $80 \%$ maternal deaths in South East Asia. $^{3,4}$ Poor fetal outcome are directly related to maternal anaemia causing growth retardation, birth asphyxia, neonatal morbidities and mortality. This study helps to analyse the high prevalence of anaemia in labouring patients despite maternal welfare programmes being run at National and International levels. It should make the health care system conscious to upgrade and do reality check on the efforts being done in these programmes. This will not only decrease the unnecessary load on hospitals, blood banks and state expenses but will also reduce the risk to patients because of severe anaemia

\section{METHODS}

A prospective observational study was conducted on 300 pregnant women presenting in labour in third trimester, Govt Doon Medical College from Oct 2019 to Dec 2019. 
These women belonged to Dehradun and surrounding hill areas. After fulfilling the inclusion criteria, the selected 300 women were subjected to detailed history, clinical examination and investigations.

\section{Inclusion criteria}

- Gestational age confirmed to third trimester, irrespective of their antenatal visits or booking.

\section{Exclusion criteria}

- Patients with blood dyscrasias, haemoglobinopathies, chronic medical illness or history of blood transfusions in previous two weeks were excluded.

Patients in first or second trimester were also excluded. The selected patients were analysed in detail mainly by age, socio demographic status, gestational age, severity of anaemia and associated obstetrical complications. Gestational age at the time of admission was categorized as preterm if $<37$ weeks, low birth weight was categorized as $<2.5 \mathrm{~kg}$.

Anaemia was classified based on WHO criteria; $\mathrm{Hb}<11$ $\mathrm{g} / \mathrm{dl}$ was considered anaemic, $\mathrm{Hb}$ concentration of 10 $10.9 \mathrm{~g} / \mathrm{dl}$ were considered in mild. 7-9.9 g/dl $\mathrm{Hb}$ was considered moderate and less than $7 \mathrm{~g} / \mathrm{dl}$ were put in severely anaemic.

The investigations conducted on patients were haemoglobin, complete blood count, blood grouping, peripheral smear and obstetrical scan. Patients were also analysed for associated obstetrical complications at admission, intra and postpartum e.g., pre-eclampsia, preterm labour, growth retardation (IUGR), abruption, $\mathrm{PPH}$.

These patients were observed in management of anaemia by either blood transfusions or intravenous iron therapy. Mean and standard deviations were used.

\section{RESULTS}

It is observed from Table 1 that the maximum number of patients belonged to reproductive age group of 21-30 years $(56.6 \%)$, followed by $32-40$ years age group (26.6\%). The illiterate group is far exceeding the literate group in having high prevalence of anaemia. It is also seen that in Muslim patients in this study form $57.1 \%$ of anaemic group. Multiparity is also seen contributing maximum number of anaemic patients $(57.14 \%)$.

It is observed that maximum number of patients belong to anaemic group mainly in the moderate and severe category.

Table 3 indicates that microcytic hypochromic anaemia is in maximum percentage which is commonly due to nutritional deficiencies.
Table 1: Prevalence of anaemia according to sociodemographic status.

\begin{tabular}{|lll|}
\hline Status & Anaemic & Normal \\
\hline Age & & \\
\hline$<20$ years & 30 & 20 \\
\hline 21-30 years & 120 & 50 \\
\hline 32-40 years & 60 & 20 \\
\hline Educational status & & \\
\hline Illiterate & 130 & 60 \\
\hline Literate & 80 & 30 \\
\hline Religion & & \\
\hline Hindu & 70 & 40 \\
\hline Muslim & 120 & 45 \\
\hline Others & 20 & 5 \\
\hline Gravida & & \\
\hline Primi & 90 & 40 \\
\hline Multi & 120 & 50 \\
\hline
\end{tabular}

Table 2: Distribution of patients according to haemoglobin groups.

\begin{tabular}{|lll|}
\hline Groups & $\begin{array}{l}\text { Number of } \\
\text { patients }\end{array}$ & Percentage \\
\hline Non anaemic & 90 & $30 \%$ \\
\hline $\begin{array}{l}\text { Mild anaemia }(\mathrm{Hb} \\
10-10.9 \mathrm{~g} / \mathrm{dl})\end{array}$ & 59 & $19.6 \%$ \\
\hline $\begin{array}{l}\text { Moderate anaemia } \\
(\mathrm{Hb} 7-9.9 \mathrm{~g} / \mathrm{dl})\end{array}$ & 88 & $29.35 \%$ \\
\hline $\begin{array}{l}\text { Severe anaemia } \\
(\mathrm{Hb}<7 \mathrm{~g} / \mathrm{dl})\end{array}$ & 63 & $21 \%$ \\
\hline
\end{tabular}

Table 3: Distribution of patients according to peripheral smear.

\begin{tabular}{|lll|}
\hline Type of anaemia & Number of cases & Percentage \\
\hline $\begin{array}{l}\text { Microcytic } \\
\text { hypochromic }\end{array}$ & 170 & $80.9 \%$ \\
\hline Dimorphic & 40 & $19.1 \%$ \\
\hline
\end{tabular}

Table 4: Distribution of patients according to gestational age.

\begin{tabular}{|lll|}
\hline Groups & Term $(>=37$ weeks $)$ & $\begin{array}{l}\text { Preterm } \\
(<37 \text { weeks })\end{array}$ \\
\hline Non anaemic & 82 & 8 \\
\hline Anaemic & 150 & 60 \\
\hline
\end{tabular}

Anaemic group is seen contributing maximum number of patients to preterm group, as observed in Table 4. Associated complications in anaemic group is observed to be considerably high compared to non-anaemic group as found in Table 5.

It is seen that the risk of association of pre term birth and small for dates babies is maximum with severe anaemia and moderate anaemia. 
Table 5: Distribution of total number of patients according to associated complications.

\begin{tabular}{|lll|}
\hline Complications & Anaemic group (210) & Non-anaemic group (90) \\
\hline Intrauterine growth retardation (on scan) & $42(20 \%)$ & $6(6.5 \%)$ \\
\hline Pre-eclampsia & $52(25 \%)$ & $8(7.2 \%)$ \\
\hline Prematurity & $60(28.5 \%)$ & $8(7.2 \%)$ \\
\hline Abruptio & $2(1 \%)$ & - \\
\hline Intrauterine death & $1(0.5 \%)$ & - \\
\hline Requirement of blood transfusions & $200(95 \%)$ & $2(1.8 \%)$ \\
\hline
\end{tabular}

Table 6: Birth out come by maternal pregnancy anaemia and haemoglobin groups.

\begin{tabular}{|c|c|c|c|c|c|c|c|}
\hline \multirow[t]{2}{*}{$\begin{array}{l}\text { Pregnancy haemoglobin } \\
\text { groups (g/dl) }\end{array}$} & \multirow[t]{2}{*}{$\begin{array}{l}\text { No. of } \\
\text { women }\end{array}$} & \multicolumn{2}{|c|}{ Preterm birth } & \multicolumn{2}{|c|}{$\begin{array}{l}\text { Small for date babies } \\
(<2.5 \mathrm{~kg} \text { birth weight })\end{array}$} & \multicolumn{2}{|l|}{ Still birth } \\
\hline & & Number & $\%$ & Number & $\%$ & Number & $\%$ \\
\hline \multicolumn{8}{|l|}{2 groups } \\
\hline Anaemic & 210 & 60 & $28.5 \%$ & 42 & $20 \%$ & 2 & $0.9 \%$ \\
\hline Non-anaemic & 90 & 8 & $8.8 \%$ & 6 & $6.67 \%$ & - & - \\
\hline \multicolumn{8}{|l|}{4 roups } \\
\hline Mild & 59 & 4 & $1.9 \%$ & 2 & $0.95 \%$ & - & - \\
\hline Moderate & 88 & 16 & $7.62 \%$ & 10 & $4.76 \%$ & 1 & $2.1 \%$ \\
\hline Severe & 63 & 40 & $19.05 \%$ & 30 & $14.29 \%$ & 1 & $2.1 \%$ \\
\hline Non-anaemic & 90 & 8 & $8.8 \%$ & 6 & $6.67 \%$ & - & - \\
\hline
\end{tabular}

\section{DISCUSSION}

In this study of pregnant women in third trimester in labour have shown a very high prevalence of incidence of anaemia $70 \%$ almost. Higher prevalence was observed by Viveki et al, Agarwal et al and Gautam which happen to be $82 \%-96 \% .^{5,7}$

In India the prevalence of anaemia is directly proportional to low socio-economic status, poor nutrition and illiteracy. Indian Council of Medical Research surveys have shown that $70 \%$ of pregnant women in our country are anaemic. ${ }^{6}$

Global data shows that $56 \%$ of pregnant women in lowand middle-income countries have anaemia. ${ }^{7}$ Prevalence is highest amongst pregnant women in Sub-Saharan Africa (57\%) followed by pregnant women in South- East Asia (48\%) and lowest in South America.

The cause of anaemia during pregnancy are multifactorial which include micronutrient deficiency of iron, folate, vitamin $\mathrm{A}$ and $\mathrm{B} 12$ and anaemia due to parasitic infections such as malaria, hookworms, or chronic infections like tuberculosis, HIV. ${ }^{8,9}$

In the present study microcytic hypochromic anaemia was the most common (86\%) type of anaemia found which is comparable to Awasthi et al (66.5\%). ${ }^{10}$

In a study by Vemulapalli B et al, $41 \%$ had moderate degree of anaemia and $6.2 \%$ of pregnant population had severe degree of anaemia. ${ }^{11}$ Findings in our present study were about $29.33 \%$ moderate and $21 \%$ with severe anaemia of all anaemic patients.

Women who were literate were less likely to be anaemic compared to their counterparts. Education has been reported to reduce the risk of being anaemic in several studies. Educated women have better income and eat nutritious food and hence do not get anaemic. ${ }^{12}$ Similar findings in this study have been observed.

In this study, the pregnancy complications associated with the anaemic group (mainly moderate and severe) were primarily maximum and were prematurity, IUGR, pre-eclampsia, PPH and abruptio. It is comparable to study by Awasthi A et al. ${ }^{10}$

In this study, association of multiparity with presence of severe anaemia was observed which is similar to study conducted by Alemayehu Bekele in Ethiopia where short birth interval was significantly associated with anaemia. Upon conception and with progression of gestation, the reproductive physiology of women is marked by the higher demand of haemoglobin due to increased requirement of iron for the growing foetus and placenta. The increased demand of fresh haemoglobin, the inability of women to produce it endogenously due to poor iron supplementation in their diet and depleted iron reserve causes maternal anaemia. Persistent anaemia significantly contributes to gestational complications and adverse birth outcomes. The main contributor group for moderate and severe anaemia are mainly multipara with repeated 
pregnancies belonging to low socio-economic status and illiteracy.

Present observation of high prevalence of anaemia about $70 \%$ in this region is preventable burden on health system. However no maternal mortality was observed in this study but this observation suggests that early diagnosis and treatment of anaemia is desirable to avert all adverse outcomes and morbidities. Upgrading our national programmes and auditing them strictly on regular basis is demand of the time. Low birth rate and pre maturity also causes a great challenge for neonatologists, which over burdens the neonatal facilities of hospitals unnecessarily.

\section{CONCLUSION}

In this study it is concluded that prevalence of anaemia is very high amongst pregnant women in labour. This finding rings an alarm to do a reality check of various maternal welfare programmes being run by health system at primary level. There is an urgent need of increasing the awareness of nutrition and supplementation amongst young women and pregnant mothers by regular workshops and media propaganda. The provision of contraceptives to young reproductive females so that spacing of pregnancies is ideal to improve maternal and fetal outcome. Upgradation of health workers at primary health centres and collecting data regarding anaemia status of a community is a must. Early diagnosis and early correction of anaemia will definitely decrease the maternal mortality as well as neonatal deaths. Preterm and low birth weight is still the leading causes of neonatal deaths in developing countries, which are frequently seen in association with anaemic mothers.

The efforts should be to correct anaemia before women enters pregnancy state. The use of blood transfusions to correct severe anaemia at term is a huge financial and work burden on blood banks, which can easily be avoided, if anaemia correction is done before the pregnant women reaches term. The requirement of educating women regarding their health should ideally begin very early before they enter reproductive age group.

\section{ACKNOWLEDGMENTS}

Authors would like to thank the women for participating in this study, the residents in labour room and the chief medical superintendent women hospital Government Doon Medical College, Dehradun, Uttarakhand, India.

Funding: No funding sources

Conflict of interest: None declared
Ethical approval: The study was approved by the Institutional Ethics Committee

\section{REFERENCES}

1. Marahatta R. Study of anaemia in pregnancy and its outcome in Nepal Medical College teaching hospital, Kathmandhu, Nepal. Med Coll J .2007;9:270-4.

2. Kalaivani K. Prevalence and consequences of anaemia in pregnancy. Indian $\mathrm{J}$ Med Res. 2009;130:627-33.

3. Mbule MA, Byaruhanga YB, Kabahenda M, Lubowa A. Determinates of anaemia among pregnant women in rural Uganda. Rural Remote Health. 2013;13:2259.

4. WHO. The global prevalence of anaemia in 2011. Geneva: world health organization; 2015.

5. Viveki RG, Halappanavar AM, Viveki PR, Halki SB, Maled VS. Prevalence of anaemia and its epidemidogical determinants in pregnant women. $\mathrm{Al}$ Ameen J Med Sci. 2012;5:216-23.

6. Kalaivani K. Prevalence and amp; consequences of anaemia in pregnancy." Indian J Med Res. 2009;130(5):627-633.

7. Agarwal KN, Agarwal DK, Sharma A, Sharmak, Prasad K, Kalita MC, et al. Prevalence of anaemic in pregnant and lactaling women in India. Indian J Med Res. 2006;124:173-84.

8. Msuya SE, Hussien TH, Yriyo J, Dam NE, StrayPedersen B. Anaemia among pregnant women in northern Tanzania: Prevalence, risk factors and effect on perinatal outcomes. Tanzania J Health Res. 2011;12(1):33-9.

9. Onorge S, Camphell O, Mirembe F. Haemoglobin status and predictors of anaemia among pregnant women in Mpigi, Uganda. BMC Res Notes. 2014;T(1):712.

10. Awasthi A, Thakur R, Dave A. Maternal and perinatal out come in cases of moderate and severe anaemia. J Obstet Gynecol India. 2001;51(6):62-5.

11. Vemulapalli B, Rao KK. Prevalence of anaemia among pregnant women of rural community in Vizianagaram, North Coastal Andhra Pradesh, India. Asian J Med Sci. 2013;5:21-5.

12. Vivek RG, Halappanavar AB, Vivek PR, Halki SB, Maled VS, Deshpande PS. Prevalence of anaemia and its epidemiological. Determin Pregnat Women. 2012;5(3):216-23.

Cite this article as: Goyal N, Pandey H. Study on prevalence of anemia in pregnant women in labour. Int J Reprod Contracept Obstet Gynecol 2020;9:2725-8. 